\title{
CALCULATION OF PARAMETERS IN THE ENGAGEMENT FIELD OF WORM GEARS
}

\author{
MUMINOVIC, A[dil] \& REPCIC, N[edzad]
}

\begin{abstract}
In order to optimally design the worm gears in terms of the temperature (the heat) limit, it is necessary to have the knowledge of the operation losses. In addition to the applied lubricant that influences the efficiency degree, the geometry of gearing also plays a significant role by the conditions necessary for the hydrodynamic lubrication. The work presented here provides a mathematical model for description of the engagement geometry and solving the problem of worm gears lubrication (calculation of loss of power). Based on the presented mathematical model, the own computer program has been developed that enables rapid analysis of parameters in the engagement field (the engagement surface, the sliding velocities, the summary velocities, the equivalent radius of curvature in the contact points of the engagement field).

Keywords: worm, gear, geometry, efficiency
\end{abstract}

\section{INTRODUCTION}

Research of worm gears has first of all been aimed at the increase of loading [1], prolongation of life cycle, enlargement of efficiency and reduction of price [2-5]. A large share of sliding by sliding-rolling movement of gearing contributes on the one hand to quiet work but on the other hand causes significant losses of power. Very often the limit of loading is not the loading capacity of gearing but the possibility to carry away the heat caused by losses. This work gives a computer provided analytical procedure for description of the engagement geometry and efficiency calculation of cylindrical worm gears with $\mathrm{ZA}, \mathrm{ZH}, \mathrm{ZE}$ and $\mathrm{EV}$-profile of worm. This calculation model discovers all contact points of one contact line during the teeth meshing, and then replaces parts of the contact line between two contact points with rolling pairs which have parallel axes (figure 1.) and which are in stationary motion.

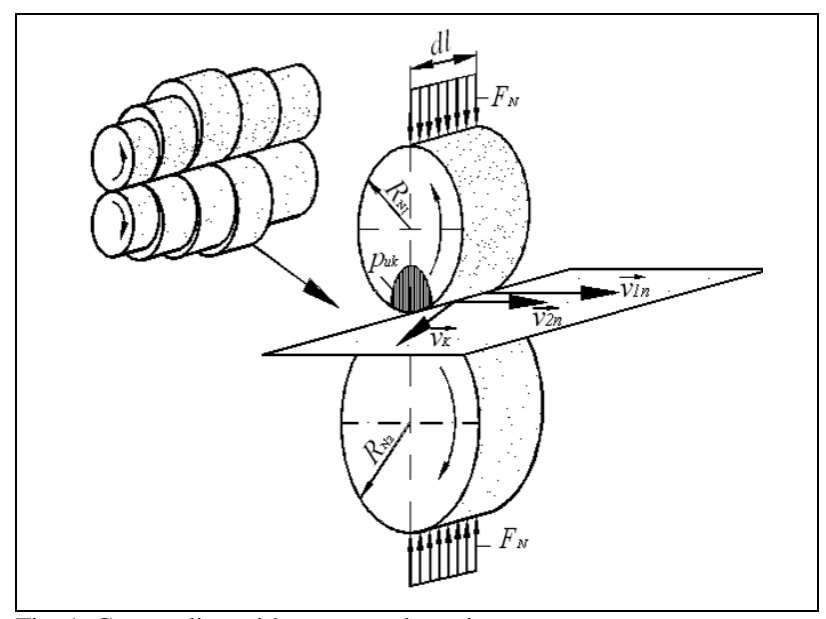

These rolling pairs have radii equal to the mean value of the worm and worm gear profile curvature radius in the adjoining points of the part of contact line. The rolling pairs, which replace the parts of contact lines approximately, present the condition of lubrication in the place of contact lines during the contact of worm and worm gear, [6] and [7].

\section{CALCULATION OF LOAD CAPACITY AND LOSSES OF POWER}

\subsection{Description of the profile of worm in axial section}

For the mathematical description of worm tooth flank, the orthogonal coordinate system was used (figure 2).

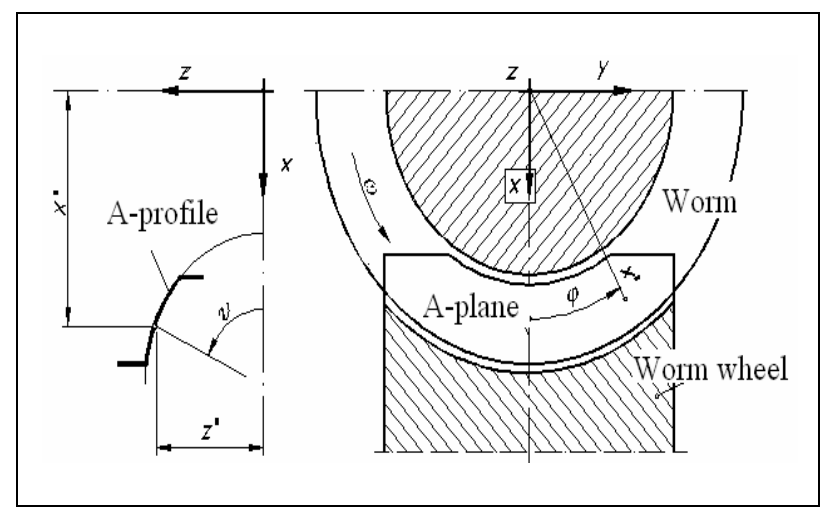

Fig. 2. Coordinate systems

Coordinates of the surface of the tooth flank can be determined by using the following equations

$$
\begin{gathered}
x=x^{\prime}(v) \cdot \cos \varphi \\
y=x^{\prime}(v) \cdot \sin \varphi \\
z=z^{\prime}(v)+\frac{h}{2 \pi} \cdot \varphi
\end{gathered}
$$

where $h$ - is axial pitch.

For $\varphi=0$ we get the equations of tooth flank in axial section (A-profile). A-profile can have different curves, depending on the production process. Types of profiles analyzed in this paper are shown in figure 3 . 

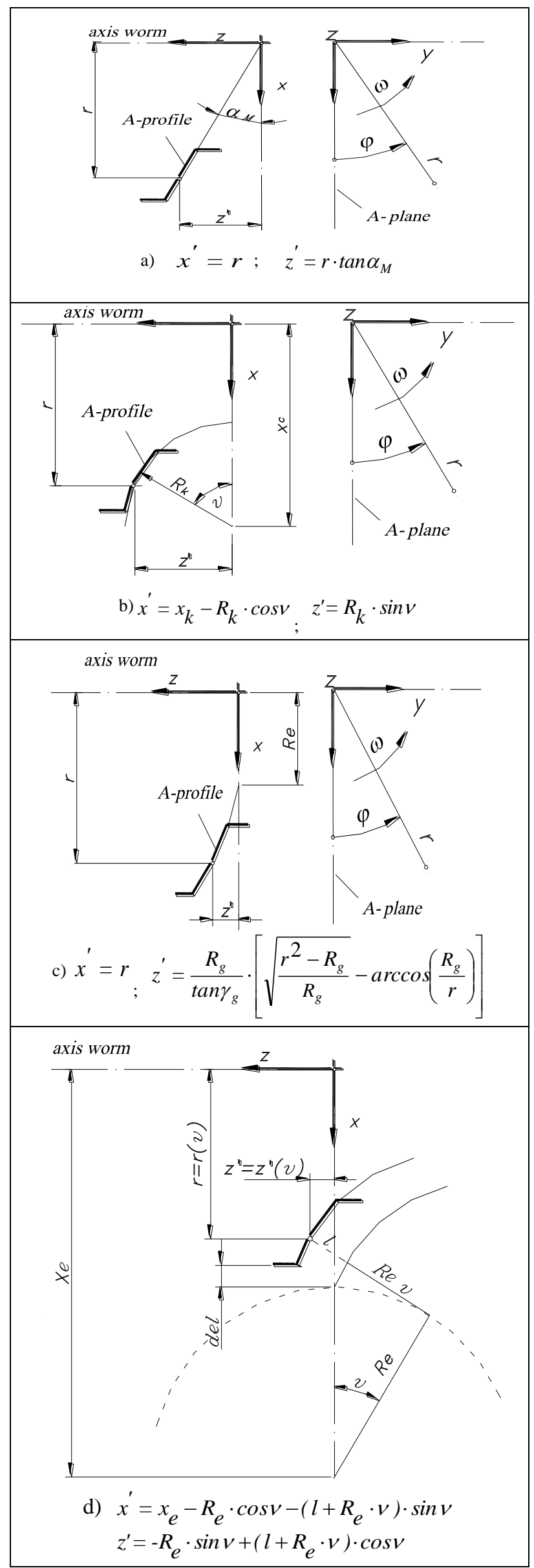

Fig. 3. Forms profiles worm: a) ZA - Archimedes spiral worm; b) $\mathrm{ZH}$ - concave worm; c) $\mathrm{ZE}$ - involutes worm; d) EV- involutes concave worm

\subsection{Load capacity and losses for a specific position of} worm

To calculate the necessary values for the load capacity and losses in a specific position of the worm, the integration across all contact lines in simultaneous engagement of teeth is performed. For the calculation of worm gears with regard to their load capacity and power losses by Hertz's theory of contact pressures, equations from [2] and [5] have been used. The load capacity and power losses of gearing are expressed in the following equations by the moment of rotation at the outlet. As in one position of the worm $\mathrm{k}\left(\mathrm{k}=1,2, \ldots, \mathrm{m}_{\mathrm{P}}, \mathrm{m}_{\mathrm{P}}\right.$ - number of worm position or division of engagement field) several contact lines are in engagement at the same time $\left(\mathrm{i}=\mathrm{k}, \mathrm{k}+\mathrm{m}_{\mathrm{P}}, \mathrm{k}+2 \mathrm{~m}_{\mathrm{P}}, \ldots, \mathrm{n}_{\mathrm{dl}}\right)$, the load capacity and energy loss for the specific position of the worm $\mathrm{k}$ are calculated as the sum of values for the contact lines engaged at the same time:

$$
\begin{aligned}
& T_{2, \mathrm{k}}=2 r_{02} \sum_{i=\mathrm{k}, \mathrm{k}+\mathrm{mP}, \cdot}^{\mathrm{n}_{\mathrm{dl}}} \int_{\text {linij } \mathrm{a}, i} k_{H} R^{*} \cos \tau d l \\
& T_{\mathrm{g} 2, \mathrm{k}}=\frac{2}{\omega_{2}} \sum_{i=\mathrm{k}, \mathrm{k}+\mathrm{mP},}^{\mathrm{n}_{\mathrm{dl}}} \int_{\text {linija }, i} k_{H} \mu R^{*} v_{K} d l
\end{aligned}
$$

In these equations are:

$r_{02}(\mathrm{~mm})$ - Pitch radius of worm gear, $\omega_{2}\left(s^{-1}\right)$ - angular velocity of worm gear, $k_{H}(\mathrm{MPa})$ - rolling pressure by Stribeck, $\mu$ - coefficient of friction, $\mathrm{R}^{*}(\mathrm{~mm})$ - relative radius of curvature, $v_{K}$ - sliding velocity, $d l$ - contact line element.

In the computer program, integration is replaced by the sum of contact line elements dl, i.e. the computer program operates with discreet points on contact lines. The energy loss of gearing $\operatorname{Tgz}_{2, \mathrm{k}}$, for position $\mathrm{k}$, could be determined if rolling pressure $\mathrm{k}_{\mathrm{H}}$ or the load per unit length $F_{N}$ on the teeth flanks and coefficient of friction $\mu$ along the contact line are known. The determination of load per unit length $\mathrm{F}_{\mathrm{N}}$ is possible only by iterative procedure on the basis of the output rotation moment $\mathrm{T}_{2}$. Based on the value of the average contact pressure $\mathrm{k}_{\mathrm{HS}, \mathrm{k}}$ for the position of worm $\mathrm{k}$ it is possible to determine the load per unit length $\mathrm{F}_{\mathrm{N}}(\mathrm{i}, \mathrm{j})$,k of the contact line element $\mathrm{dl}(\mathrm{i}, \mathrm{j}), \mathrm{k}$ as follows:

$$
F_{N}(i, j)_{\mathbf{k}}=2 R^{*}(i, j) f_{H}(i, j) k_{\mathbf{H} S, k}
$$

The factor of contact pressure distribution $f_{H}$ in previous equation can describe the distribution of this pressure on one contact line; approach used in [4]. The known load per unit length makes it possible to model the coefficient of friction in the contact point of contact line, thereby also the calculation of the gearing loss of energy by equation (3).

The distribution of maximum load and power losses throughout the whole engagement field plays a very important role in judging the worm gear. This enables the determination of areas of high and low maximum load and power-losses. For certain specific quantities, the 
following non-dimensional expressions are obtained according to [5]:

Specific maximum load based on rolling pressure:

$$
D I P / D L S=R^{*} \cdot \cos \tau \frac{d l}{a \cdot d l s}
$$

Specific losses based on the friction factor $\mu$

$$
D I P G / D L S=R^{*} \cdot v_{K} \frac{d l}{a^{2} \cdot d l s \cdot \omega_{1}}
$$

The total maximum load and power losses of the worm gear are obtained as the average value of maximum load and power loss for all positions of the worm within one division of the engagement field. By introducing non-dimensional quantities, comparative quantities $U$, which are independent of the drive quantities $\left(\omega_{1}, k_{H} \mu\right)$ and of the gear size (axle distance $a$ ). In this case the comparative quantities shall solely depend upon the shape of the worm profile, i.e. the tooth geometry. The expressions for non-dimensional comparative quantities are:

Maximum load based on roller pressure

$$
U_{2}=\frac{1}{k_{H} \cdot a^{3}} T_{2}
$$

Relative losses of toothing based on the friction factor

$$
U_{g z}=\frac{1}{\mu} \cdot \frac{T_{g z 2}}{T_{2}}
$$

With the help of these comparative quantities, the maximum load and losses for a certain worm gear can be determined in all working conditions, if all drive quantities are known.

\section{CALCULATION OF PARAMETERS IN

\begin{tabular}{|c|c|c|c|c|}
\hline \multicolumn{5}{|l|}{ a) Input data } \\
\hline \multirow{2}{*}{\multicolumn{2}{|c|}{ Parameter }} & \multicolumn{3}{|c|}{$\begin{array}{l}\text { Shape profile in axial } \\
\text { section (A-profile) }\end{array}$} \\
\hline & & ZA & $\mathrm{ZH}$ & ZE \\
\hline \multicolumn{2}{|l|}{ Center distance } & \multirow{7}{*}{\multicolumn{3}{|c|}{$\begin{array}{l}\mathrm{a}=90(\mathrm{~mm}) \\
z_{2}=2 \\
z_{2}=36 \\
r_{\mathrm{m} 1}=18(\mathrm{~mm}) \\
n_{1}=1500\left(\mathrm{~min}^{-1}\right) \\
\mu=0,1 \\
k_{\mathrm{Hz}}=2,5(\mathrm{Map})\end{array}$}} \\
\hline \multicolumn{2}{|c|}{ Number of worm teeth } & & & \\
\hline \multicolumn{2}{|c|}{ Number of worm wheel teeth } & & & \\
\hline \multicolumn{2}{|c|}{ Pitch radius of worm } & & & \\
\hline \multicolumn{2}{|l|}{ Worm input speed } & & & \\
\hline \multicolumn{2}{|l|}{ Coefficient of friction } & & & \\
\hline \multicolumn{2}{|c|}{ Rolling pressure by Stribeck } & & & \\
\hline Factor of profile shift & $x_{2}(--\quad)$ & 0 & 1,5 & 0 \\
\hline Axial module & $m \quad(\mathrm{~mm})$ & 4 & 3,6 & 4 \\
\hline \multirow{4}{*}{$\begin{array}{l}\text { Geometrical parameters } \\
\text { for the description of } \\
\text { the profile in axial } \\
\text { section }\end{array}$} & $\alpha_{\mathrm{M}}\left({ }^{\circ}\right)$ & 20 & - & - \\
\hline & $x_{\mathrm{K}}(\mathrm{mm})$ & - & 24 & - \\
\hline & $R_{\mathrm{K}}(\mathrm{mm})$ & - & 17 & - \\
\hline & $R \mathrm{~g}(\mathrm{~mm})$ & - & - & 9,2 \\
\hline \multicolumn{5}{|c|}{ b) Calculated data (mean values) } \\
\hline Radius of curvature & $R^{*}(\mathrm{~mm})$ & 24 & 185 & 18,8 \\
\hline Sliding velocity & $v_{\mathrm{K}}(\mathrm{m} / \mathrm{s})$ & 2,9 & 2,94 & 2,88 \\
\hline Sliding-rolling ratio & $V_{\mathrm{k}} / V_{\mathrm{sum}}$ & 2,68 & 1,25 & 2,72 \\
\hline Maximum load & $T_{2}(\mathrm{Nm})$ & 420 & 885 & 368 \\
\hline
\end{tabular} THE ENGAGEMENT FIELD}

Input data in a computer program for the worm gear discussed in this paper are given in table 1 (part $a$ ).
Table 1. Input and calculated data

By using the computer program, the contact lines within the engagement field of worm gear, the radius of curvature, the sliding-rolling ratio and the mean values for the radius of curvature, the sliding velocity, the sliding-rolling ratio and the maximum load, are calculated and shown in table 1 (part $b$ ).

Figure 4 shows the results of calculation of parameters in the engagement field for the ZA-profile of worm gear. Calculation results include the outline of the engagement surface (a), the sliding velocities (b), the summary velocities (c) and the equivalent radius of curvatures in the engagement field's contact points (d).

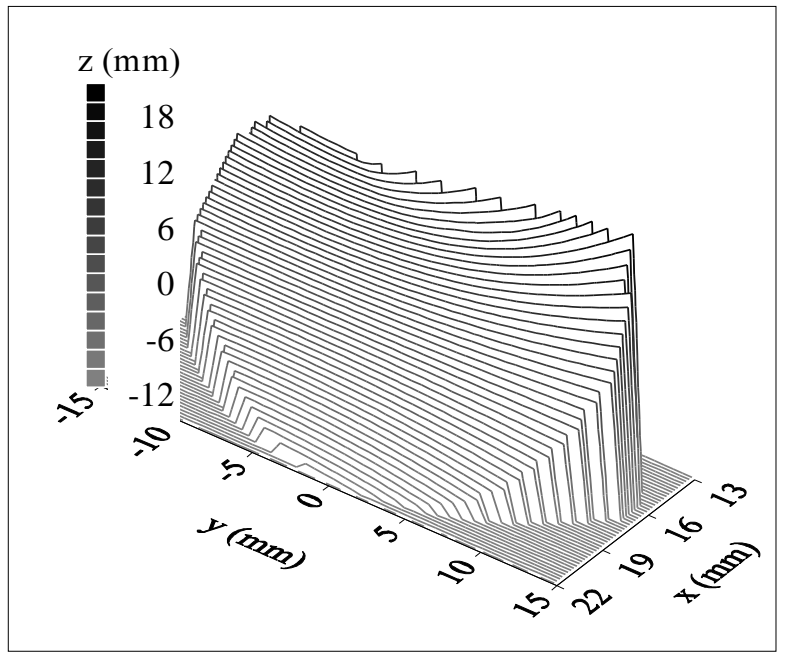

a)

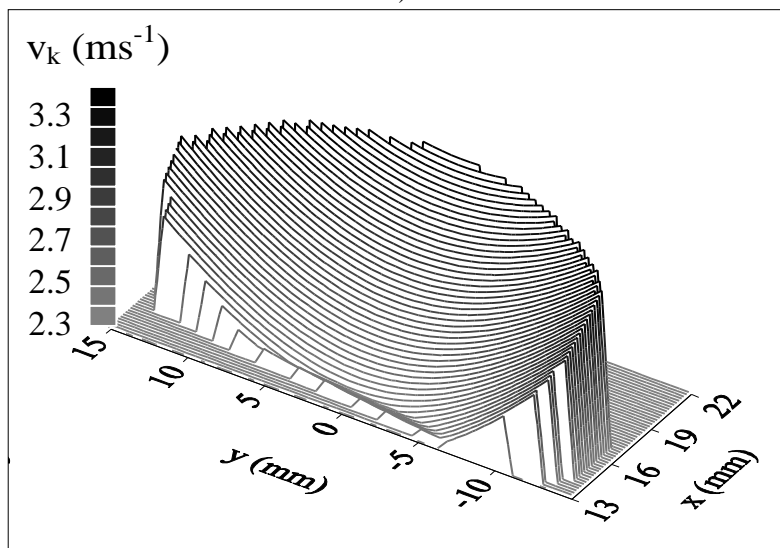

b)

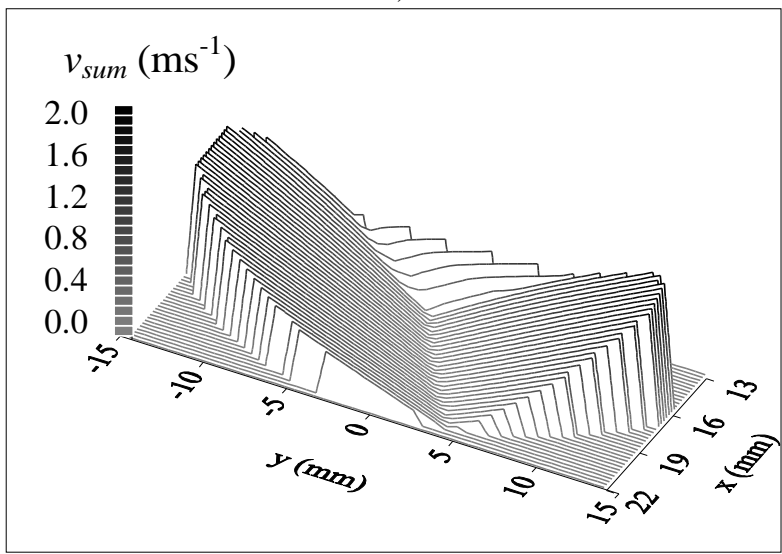

c) 


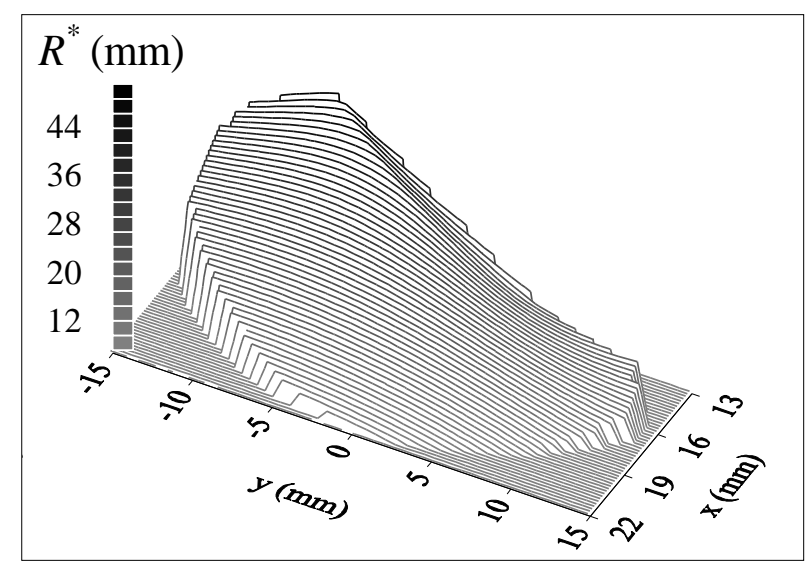

d)

Fig. 4. Basic parameters in the gear engagement field for the ZAprofile: a) contact lines (engagement field), b) rolling velocity, c) sliding velocity and d) relative radius of curvature.
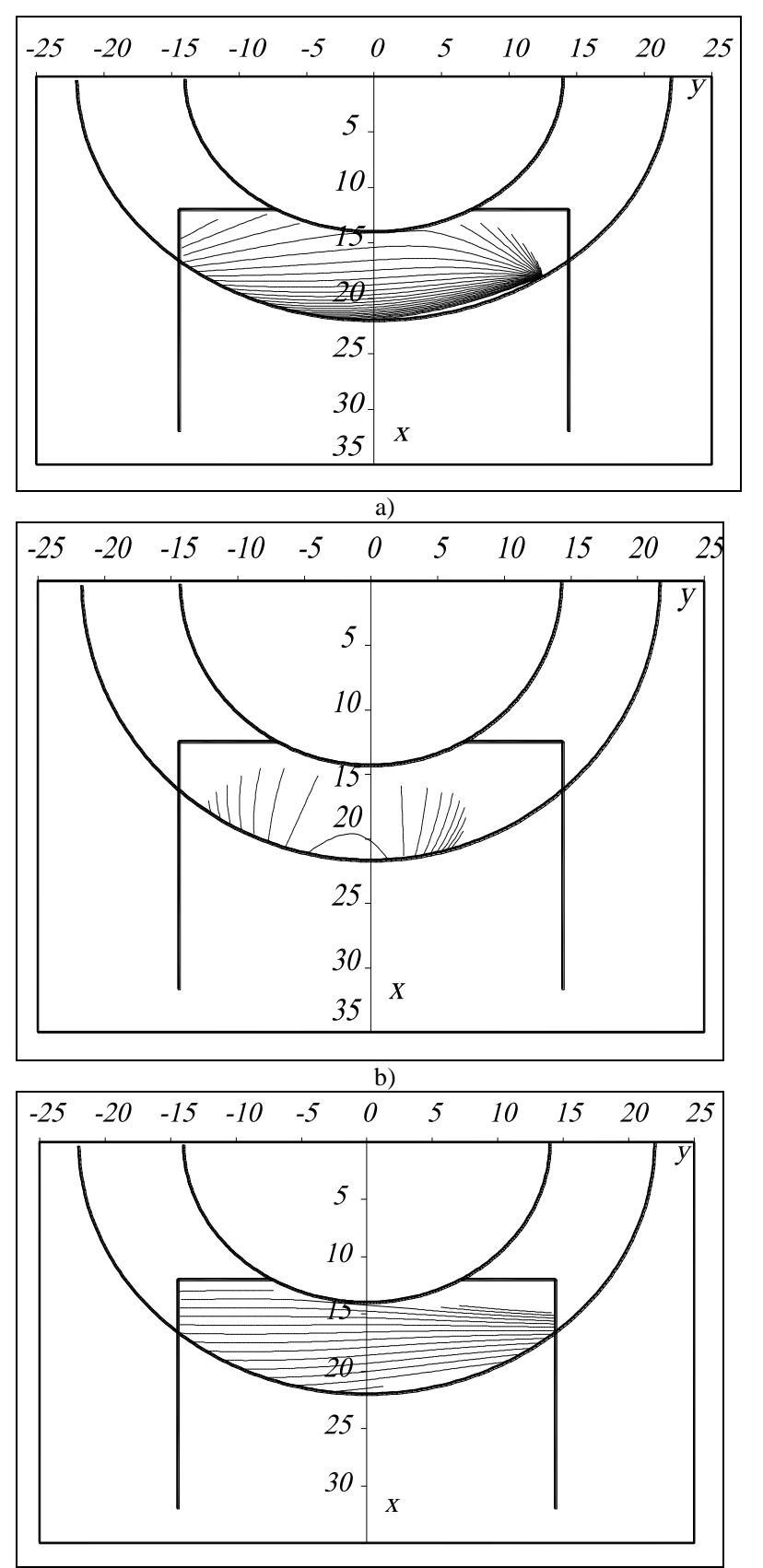

c)

Fig. 5. Representation of contact lines of the worm gear: a) $\mathrm{ZH}$ - profile $\mathrm{x}=0$, b) $\mathrm{ZH}$ - profile $\mathrm{x}=1.5$, c) $\mathrm{ZE}$ - profile $\mathrm{x}=0$
Figure 5 shows graphical representation of contact lines within the engagement field for the tested $\mathrm{ZH}$ (cases when the factor of profile shift $\mathrm{x}=0$ and $\mathrm{x}=1,5)$ and $\mathrm{ZE}$ profile of worm gear.

\section{CONCLUSION}

Based on the analysis conducted in this paper, it can be concluded that the newly developed computer program provides:

- The calculation of basic parameters in the engagement field needed to analyze the efficiency and load capacity of worm gear.

- Formalization of the process of worm gear design, with the ultimate goal of an integrated design by utilizing computer.

With appropriate additions, mathematical model and computer program can be also applied for solving similar problems in case of other types of gear transmissions.

The contribution of this work to technology may be recognized in the fact that the developed calculation method with the use of computer capabilities enables the calculation of efficiency and maximum loads for different profile shapes of the worm side in axial crosssection, for various geometrical dimensions of the worm gear, with minor corrections. This implies major significance, considering the great capabilities of production using $\mathrm{CNC}$ machines which would maybe enable the discovery of the optimal profile of the worm gear teeth, using the developed calculation method and the computer program.

\section{REFERENCES}

[1] Opalić, M. (1984), Prilog istraživanju opteretivosti bokova pužnih kola pužnih prenosnika/ Contribution to study carrying capacity flanks of worm wheel of worm gear, Ph. D. thesis, Zagreb, Croatia

[2] Muminović, A. (2003). Istraživanje primjenjivosti termo-elastohidrodinamičkog podmazivanja kod pužnih prijenosnikal Research applicability of thermo-elasto-hydrodynamic lubrication at worm gear, Ph. D. thesis, Faculty of Mechanical Engineering, Sarajevo, Bosnia and Herzegovina

[3] Sharif, K. J.; Kong, S.; Evans, H. P.; Snidle, R. W. (2001) Contact and elastohydrodynamic analysis of worm gears, Proc Instn Mech Engrs 215C, 817-830

[4] Bouche, B. (1991). Reibungszahlen von chneckengetriebeverzahnungen im Mischreib-ungsgebiet/ Coefficient of friction of worm gear tooth contact in the mixed friction, Ph. D. thesis, Bochum

[5] Wilkesmann, H. (1974) Berechnung von Schneckengetrieben mit unterschiedlichen-Zahnprofilformen/ Calculation of worm gears with different tooth profile shapes, $\mathrm{Ph}$. D. thesis, TU München, München

[6] Szeri, A. Z. (1998). Fluid Film Lubrication - Theory and Design, Cambridge University Press, New York

[7] Muminović, A.; Kljajn, M.; Risović, S. (2006). Mathmatical Model for Calculation of Efficiency of Worm Gear Drives Strojarstvo, Journal for Theory and Application in Mechanical Engineering, (0562-1887) 48 (2006), 5-6; 293-301, Croatia 